\title{
Neutrophils and tumour necrosis factor- $\alpha$ are important for controlling early gastrointestinal stages of experimental murine listeriosis
}

\author{
J. W. CONLAN* \\ Trudeau Institute Inc., Saranac Lake, New York 12983, USA
}

\begin{abstract}
The present study examined the need for neutrophils and tumour necrosis factor- $\alpha$ (TNF $\alpha$ ) for early defence against gut infection with the enteroinvasive, facultative intracellular bacterial pathogen, Listeria monocytogenes. Mice were treated with a neutrophil-depleting monoclonal antibody (MAb) or a MAb directed against TNF $\alpha$, and the consequences of these treatments on the course of orally initiated infection with the pathogen were monitored. By day 3 , orally initiated $L$. monocytogenes infection in mice treated with either MAb was severely exacerbated to the extent that up to 5000-fold more listeriae were recovered from the walls of the stomach, small intestine, caecum or large intestine of treated mice than from controls. Systemic infection resulting from the ingestion of $L$. monocytogenes was also severely enhanced in mice treated with these MAbs. Therefore, the results showed that neutrophils and TNF $\alpha$ have a critical role in the early defence against enteroinvasive $L$. monocytogenes infection initiated by a natural (in this case the oral) route, as well as in the control of subsequent systemic infection.
\end{abstract}

\section{Introduction}

Listeria monocytogenes is a facultative intracellular bacterium capable of causing severe infections in man as a result primarily of the ingestion of contaminated food [1]. Mice infected experimentally by the oral route develop an enteroinvasive infection resembling that which can occur in man [2]. Consequently, murine models of orally initiated listeriosis have been used to examine various aspects of $L$. monocytogenes enteroinvasion $[3,4]$. For example, studies with mice have shown [3] that L. monocytogenes invades the gut wall preferentially via the Peyer's patches (PP) in the terminal ileum of the small intestine probably, like enteroinvasive bacteria generally [5], by invading specialised epithelial microfold (M) cells that overlie these lymphoid structures. Other studies with guineapigs treated with opium to inhibit peristalsis have shown that, provided it can be retained in the gut lumen, L. monocytogenes can also invade non-specialised enterocytes throughout the length of the small intestine [6]. Regardless of its portal of entry, $L$. monocytogenes subsequently can multiply locally in PP

Received 15 Feb. 1996; revised version accepted 6 Aug. 1996.

*Corresponding author: Dr J. W. Conlan.

Present address: Institute for Biological Sciences, 100 Sussex Drive, Ottawa, Ontario K1A 0R6, Canada. and can disseminate to cause severe systemic infection [2-4].

Because $L$. monocytogenes can parasitise macrophages, host resistance to it was thought to depend mainly on specific T-cell-mediated immunity rather than on nonspecific defences [7]. This implies that, in order to kill the listeriae they ingest, macrophages must be activated by lymphokines secreted by pathogen-specific $\mathrm{T}$ cells. However, recent results [8-13] show that non-specific defences expressed by neutrophils, and mediated by the cytokine tumour necrosis factor- $\alpha$ (TNF $\alpha$ ) are critical to the control of progressive hepatic and splenic infection initiated by the parenteral inoculation of L. monocytogenes. In the absence of neutrophils or TNF $\alpha, L$. monocytogenes grows unrestrictedly in the liver and spleen to overwhelm the host rapidly before T-cellmediated immunity can be generated. T-cell-mediated immunity is required to ensure the efficient resolution of L. monocytogenes infection after early defences have been activated [14-16]. To date, studies of anti-Listeria defences have primarily used mice infected by parenteral routes. In contrast, the need for particular leucocytes and cytokines to combat this pathogen at its natural sites of implantation in the gut wall, thereby to prevent or impede disseminated infection, are largely unknown, and cannot be predicted from their involvement at other sites of infection. Indeed, for other enteroinvasive bacteria it has been suggested that neutrophils recruited into infectious 
foci in the gut wall and TNF $\alpha$ produced therein can damage surrounding intestinal epithelium $[17,18]$, and hence promote infection rather than antibacterial defence.

With these considerations in mind, the present study was undertaken to examine the effect on the course of orallyinitiated $L$. monocytogenes infection in various compartments of the gut and in the liver and spleen of depleting mice of neutrophils, or neutralising their TNE, by the use of specific monoclonal antibodies (MAbs).

\section{Materials and methods}

\section{Mice}

Young adult (9-12-week-old) male CB6/FI mice were used in all experiments. Mice were obtained from the Trudeau Institute Animal Breeding Facility, Saranac Lake, NY, USA, and were free of common viral pathogens according to routine screening procedures performed by the Research Animal Diagnostic Laboratory, University of Missouri, Columbia, USA. Animal experiments were performed in accordance with the recommendations of the National Institutes of Health Guide to the Care and use of Laboratory Animals.

\section{Bacteria}

Streptomycin-resistant strain $10403 \mathrm{~S}$ of L. monocytogenes [19] was used throughout. A stock culture of the organism was prepared in trypticase-soy broth as described previously [18], distributed in $1-\mathrm{ml}$ volumes and frozen at $-70^{\circ} \mathrm{C}$. To prepare oral inocula, stock vials were thawed, seeded into fresh trypticase-soy broth containing streptomycin sulphate $250 \mathrm{mg} / \mathrm{L}$, and grown for $4 \mathrm{~h}$ to mid-log phase at $37^{\circ} \mathrm{C}$ with shaking. These cultures were harvested by centrifugation at ambient temperature and resuspended to the required dose in saline. The size of the inoculum was determined immediately before infection by a total bacterial count with a Petroff-Hauser counting chamber and dark-field microscopy, and was subsequently confirmed by plating on trypticase-soy agar containing streptomycin sulphate $250 \mathrm{mg} / \mathrm{L}$ (STSA).

Bacteria were inoculated directly into the stomachs of mice in a volume of $0.2 \mathrm{ml}$ with a syringe fitted with a 19-gauge gavage needle. In preliminary studies, an intragastric inoculum of $5 \times 10^{9} \mathrm{cfu}$ (but not $\left.5 \times 10^{8} \mathrm{cfu}\right)$ of L. monocytogenes strain $10403 \mathrm{~S}$ consistently established infection in mice and was, therefore, used in all subsequent experiments. This finding is not surprising given that others [3] have shown that for mice an oral dose of $>10^{8} \mathrm{cfu}$ of the more virulent EGD strain of $L$. monocytogenes is needed to ensure infection. In another preliminary experiment, bacteria could not be isolated from the livers, spleens or lungs of a group of mice that had been inoculated intragastrically with $L$. monocytogenes
$3 \mathrm{~h}$ earlier. This indicates that accidental aspiration or parenteral injection of the inoculum is not a complication of the gavage procedure. Experimentally, mice were killed by cervical dislocation on various days after infection, and bacterial burdens in infected tissues were determined by plating serial 10 -fold dilutions of organ homogenates on STSA. To enumerate bacteria, the gastrointestinal (GI) tract was removed intact, freed of connective tissue, and dissected into its component parts of stomach, small intestine, caecum, and colon. The luminal contents of each compartment were flushed out with $60 \mathrm{ml}$ of sterile saline with a syringe fitted with a gavage needle which was inserted into the proximal incision produced by dissection. The first and last $10 \mathrm{ml}$ of wash from each GI tract compartment were collected for bacteriological examination. Peyer's patches (PP) were dissected from the washed small intestine, and homogenised and plated separately from the remainder of this tissue. Listeriae were also enumerated in the liver and spleen as a measure of the extent of systemic dissemination of infection. Colonies were counted after incubation at $37^{\circ} \mathrm{C}$ for $24 \mathrm{~h}$. Preliminary studies showed that in uninfected control mice, no bacteria could be cultured from any homogenised intestinal compartment or their contents on STSA even after incubation for $48 \mathrm{~h}$ at $37^{\circ} \mathrm{C}$, and that L. monocytogenes $10403 \mathrm{~S}$ deliberately seeded into these gut homogenates was quantitatively recovered from them on STSA. In this regard, in all experiments, only colonies characteristic of L. monocytogenes were recovered on STSA, and were considered to be the test pathogen.

\section{MAbs and MAb treatments}

Anti-granulocyte MAb RB6-8C5 is a rat $\operatorname{lgG} 2 \mathrm{~b}$ antibody that selectively depletes mice of neutrophils and eosinophils [20]. The hybridoma that secretes this MAb was a gift from Dr R. Coffman, DNAX Research Institute, Palo Alto, CA, USA. Hybridoma LTF.2 secretes a rat $\operatorname{IgG} 2 \mathrm{~b}$ MAb against keyhole limpet haemocyanin, and was produced at this Institute by $L$. Johnson et al. [21]. It was used as control MAb for experiments with RB6-8C5. Hybridoma XT311 secretes a rat IgGl MAb against mouse $\mathrm{TNF} \alpha$, and was obtained from DNAX. Hybridoma 91b secretes a rat IgG1 MAb against horseradish peroxidase [22] and served as an irrelevant isotype-matched control for anti-TNF $\alpha$ MAb. This hybridoma was provided by $\mathrm{Dr}$ C. J. Dean, Institute of Cancer Research, Surrey. MAbs were purified from ascites fluid by ammonium sulphate precipitation followed by DEAE-ion-exchange chromatography, and MAb purity was checked by SDS-PAGE. Immunoglobulin concentrations were determined by spectrophotometry or by peak height during elution from an HPLC size-exclusion column, or both.

MAb RB6-8C5 or control MAb LTF.2, was given by intraperitoneal (i.p.) injection in $0.2 \mathrm{ml}$ of saline in a dose of $0.5 \mathrm{mg} 1$ day before infection. This amount of 
RB6-8C5 has been shown $[9,10,12,20]$ to cause severe granulocytopenia for up to 5 days. In the present study, the extent of neutropenia was measured by examining blood and single cell suspensions of PP cells from a group of $L$. monocytogenes-infected mice on day 3 of infection for the presence of granulocytes. Neutrophils were $\geqslant 95 \%$ depleted at these sites in RB6-8C5-treated compared with control mice. Anti$\mathrm{TNF} \alpha \mathrm{MAb}$, which had a neutralising capacity of $3.3 \times 10^{4}$ neutralising units/mg by standard bioassay [11], and control MAb $91 \mathrm{~b}$ were given i.p. in a dose of $0.5 \mathrm{mg} 4 \mathrm{~h}$ before infection. MAb-treated mice were killed on day 3 of infection and bacteria were enumerated in their tissues as detailed above.

\section{Histology}

Pieces of washed gut wall from mice killed on day 3 of infection were fixed in buffered formalin $10 \%$ for $24 \mathrm{~h}$. Fixed tissue was dehydrated in ethanol and embedded in plastic (JB4 embedding kit; Polsciences Inc.) Thin (1-2 $\mu \mathrm{m})$ sections were cut with glass knives, stained with MacNeal's tetrachrome, and examined with a Nikon microphot-FX light microscope.

\section{Reproducibility and statistics}

All reported experiments yielded similar results on at least two separate occasions. Because bacteria were not isolated consistently from some tissue sites examined in a group of mice, statistical analyses were performed by the Mann-Whitney rank sum test; $p$ values $<0.05$ were considered significant.

\section{Results}

\section{Course of orally initiated listeriosis in} immunocompetent mice

In an initial experiment, the course of listeriosis in various GI tract compartments and the livers and spleens of mice was monitored on days 1, 2, 4 and 8 of infection. The results, presented in Fig. 1, show that most of the L. monocytogenes inoculum could not be recovered from the gut by one day after infection, and that what could be recovered was associated with the luminal contents and walls of all intestinal compartments. By day 1 , in the body of the small intestine, listeriae were preferentially recovered from the PP rather than from the remaining wall dissected free of these structures. Thus, PP, which represent $<1 \%$ of the luminal surface of the small intestine, on average contained $80 \%$ of the listeriae associated with the wall of this compartment at this time. Listeriae persisted in small numbers, and in some cases apparently multiplied, in the various gut compartments for a few days before being eliminated rapidly between days 4 and 8 . The fact that no bacteria could be cultured from any intestinal site examined on day 8 of infection, testifies to the complete inhibitory capacity of the streptomycin- containing medium used in these studies for indigenous intestinal microflora.

L. monocytogenes were isolated from the livers and spleens of some mice as early as day 1 of infection, but were not uniformly present in these organs until day 2. However, as in the gut, hepatosplenic infection had almost completely resolved by day 8 . In addition to the data presented in Fig. 1, small numbers $\left(<3.0 \log _{10} \mathrm{cfu}\right)$ of listeriae were occasionally isolated (from 5 out of 20 mice) from the stomach wall or contents during the 8 -day experimental period. Clearly, an oral dose of $5 \times 10^{9} \mathrm{cfu}$ of L. monocytogenes strain 10403S, like the more virulent EGD strain [3], represents a sublethal inoculum for immunocompetent mice.

\section{Effect of treating mice with anti-TNF $\alpha$ MAb on orally initiated listeriosis}

Studies by others $[11,23]$ have shown that early defence against parenterally initiated systemic listeriosis depends on TNF $\alpha$. However, given that TNF $\alpha$ can cause enteropathy $[17,24]$, it is possible that in the gut this cytokine might participate in disease progression rather than antibacterial defence. With this consideration in mind, an experiment was performed to examine the effect of treating mice with anti-TNF $\alpha$ MAb on the course of orally initiated listeriosis. Mice treated with this $\mathrm{MAb}$ or a control $\mathrm{MAb}$ were killed on day 3 of infection and bacterial burdens were determined at various tissue sites. The results in Table 1 show that, compared to the situation in control mice, listeriosis in mice treated with $\mathrm{TNF} \alpha$-neutralising MAb was severely exacerbated at all sites examined by day 3 $(p<0.015)$. By this time, numerous listeriae could be washed from the intestinal lumens of the MAb-treated mice. Moreover, under these circumstances, many more listeriae were flushed out in the first $10 \mathrm{ml}$ than in the last $10 \mathrm{ml}$ of wash fluid. This suggests that by day $3, L$. monocytogenes-infected mice treated with anti-TNF $\alpha$ $\mathrm{MAb}$ haboured substantial numbers of listeriae that were only loosely associated with the gut wall. However, other listeriae clearly remained firmly associated with the gut walls of these mice despite rigorous luminal washing. Overall, compared to the situation in control mice, in mice treated with antiTNF $\alpha$ MAb, infection was enhanced by $c .1000$-fold in the stomach wall and PP, and 40-250-fold elsewhere in the gut wall. In addition to the findings in the gut, $c$. 1000 -fold and 10000-fold more listeriae were recovered from the spleens and livers, respectively, of mice treated with anti-TNF $\alpha$ MAb than from these organs in mice treated with control MAb $(p<0.01)$.

The numerous listeriae that were washed from the lumina of mice treated with anti-TNF $\alpha$ MAb (Table 1) suggests that this pathogen will be excreted from these mice in large numbers. Therefore, coprophagy might contribute to the enhanced $L$. monocytogenes infection 

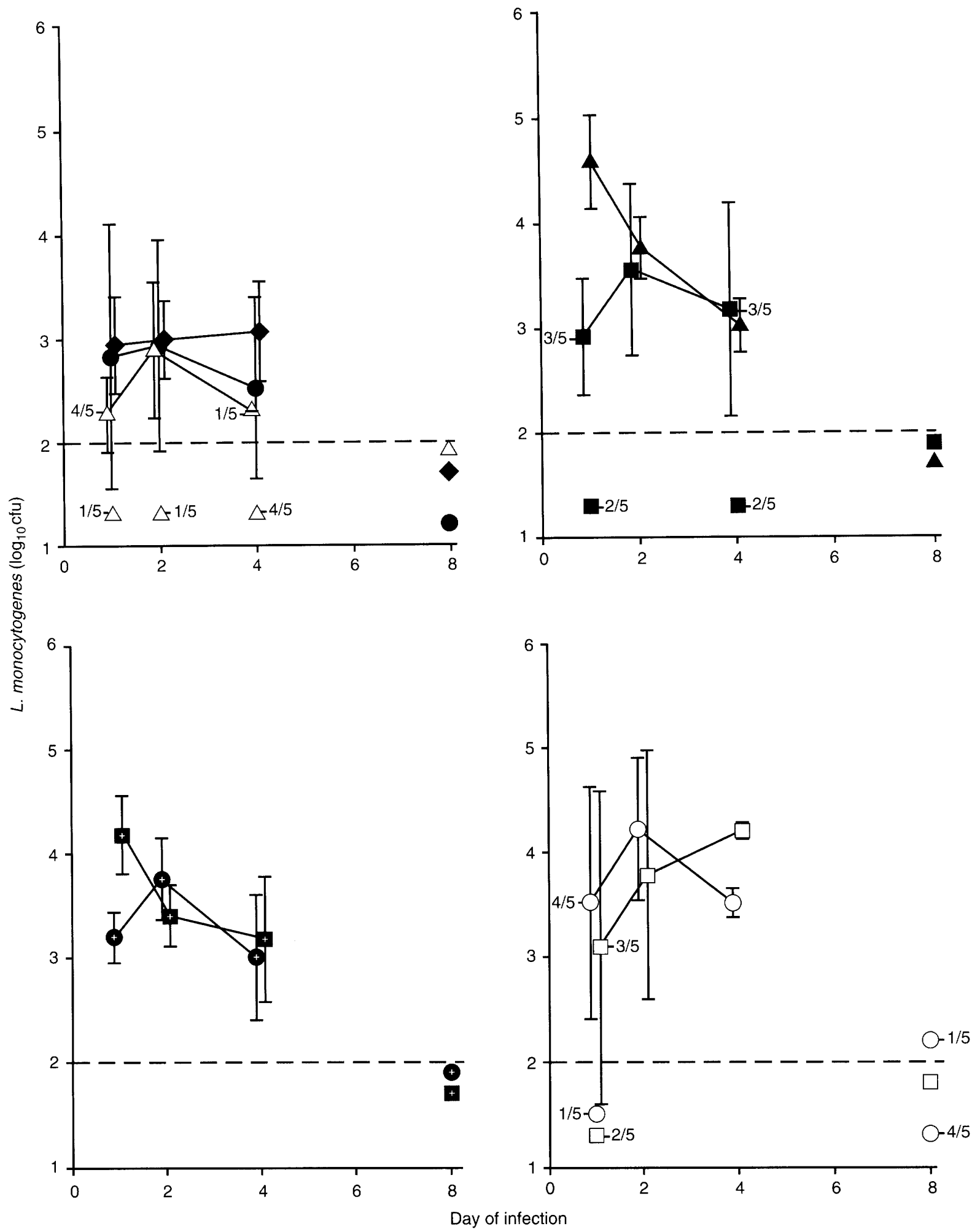

Fig. 1. Course of orally initiated listeriosis. Mice were inoculated by mouth with $5 \times 10^{9} \mathrm{cfu}$ of L. monocytogenes and bacteria were enumerated in various sites on various days of infection. Data shown are the means for five mice/group/ timepoint, except where indicated. Broken line indicates the detection limit for bacteria at all sites examined, except PP in which the detection limit was $1.3 \log _{10}$. Similar results were obtained in a repeat experiment. particles; $\triangle$, small intestinal wall; $\bullet$, small intestinal contents; $\mathbf{\square}$, caecal wall; $\boldsymbol{\Delta}$, caecal contents; $\boldsymbol{\odot}$, large intestinal wall; $\boldsymbol{+}$, large intestinal contents; $\bigcirc$, liver; $\square$, spleen.

observed in mice treated with anti-TNF $\alpha$-MAb. To test this possibility, mice treated with anti-TNF $\alpha \mathrm{MAb}$ were then either infected with $L$. monocytogenes or left uninfected. Infected and uninfected mice were co-housed and killed on day 3 of infection for bacteriological examination. In this experiment, listeriae were recovered at levels similar to those reported in Table 1 from all sites examined in mice deliberately infected and treated with anti-TNF $\alpha$ MAb (data not shown). By contrast, no listeriae were isolated from 
Table 1. Effect of anti-TNF $\alpha$ MAb treatment on orally initiated listeriosis

\begin{tabular}{lcc}
\hline & \multicolumn{2}{c}{$\log _{10}$ (SD) cfu of L. monocytogenes/tissue site } \\
\cline { 2 - 3 } Tissue sample & $\begin{array}{c}\text { Mice treated with } \\
\text { anti-TNF } \alpha \text { MAb }\end{array}$ & Control mice \\
\hline Stomach wall & $5.07(0.29)$ & $<2.00^{\dagger}$ \\
Peyer's patches & $5.31(0.38)$ & $2.18^{*}(0.70)$ \\
Small intestine wall & $4.57(0.44)$ & $<2.18_{\ddagger}^{\ddagger}$ \\
Small intestine wash 1 & $5.35(0.82)$ & $2.54(0.36)$ \\
Small intestine wash 2 & $3.29(1.09)$ & $\mathrm{ND}$ \\
Caecum wall & $4.81(0.58)$ & $3.65(0.26)$ \\
Large intestine wall & $5.21(0.64)$ & $3.65(0.26)$ \\
Large intestine wash 1 & $5.52(0.68)$ & $3.03(0.38)$ \\
Large intestine wash 2 & $2.28(0.41)$ & $\mathrm{ND}$ \\
Liver & $7.61(0.43)$ & $3.66(0.44)$ \\
Spleen & $6.79(0.35)$ & $3.98 \quad(0.89)$ \\
\hline
\end{tabular}

Mice were treated with anti-TNF $\alpha$ MAb or control MAb $4 \mathrm{~h}$ before being inoculated per os with $3.8 \times 10^{9} \mathrm{cfu}$ of $L$. monocytogenes. Infected mice were killed on day 3 for bacteriological examination. Data shown are the means of five mice/group.

Wash 1, first $10 \mathrm{ml}$ of luminal wash; wash 2, last $10 \mathrm{ml}$ of luminal wash; $\mathrm{ND}$, not determined.

*Wall dissected free of PP.

$\uparrow$ No bacteria recovered from this site in five mice.

$\$$ Bacteria recovered from three of five mice.

any uninfected cohabiting mice treated with antiTNF $\alpha$ MAb. Thus, it seems improbable that coprophagy contributes substantially to the infectious process in immunocompromised mice.

\section{Effect of depleting mice of neutrophils on orally initiated listeriosis}

Previous studies from this laboratory $[8,9,24,25]$, and elsewhere $[10,12]$, firmly established that neutrophils are crucial for combatting systemic listeriosis following the intravenous injection of $L$. monocytogenes. However, the need for neutrophils to combat enteroinvasive stages of infection in the gut caused by the oral inoculation of this pathogen is unknown, and cannot be predicted on the basis of the need for these phagocytes at other sites of infection. For instance, in the case of experimental Shigella flexneri infection in rabbits, it appears that neutrophil-mediated destruction of intestinal epithelium essentially instigates bacterial enteroinvasion [17]. With these considerations in mind, experiments were performed to determine the need for neutrophils in anti-L. monocytogenes defence in the gut. This involved treating mice with anti-granulocyte $\mathrm{MAb}$, RB6-8C5, or isotype-matched control MAb, 1 day before infecting them per os, and determining bacterial burdens in infected tissues on day 3 of infection. The extent of $L$. monocytogenes infection in both groups of mice by this time is shown in Table 2 . It shows that in neutrophil-depleted mice, L. monocytogenes infection was severely exacerbated at all sites examined to the extent that, by day $3, c .100-10000-$ fold more listeriae were recovered from sites of infection in these than in control mice $(p<0.02)$. As was the case with mice treated with anti-TNF $\alpha$ MAb, in neutropenic mice numerous listeriae remained

Table 2. Effect of depleting mice of neutrophils on orally initiated listeriosis

\begin{tabular}{lcc}
\hline & \multicolumn{2}{c}{$\log _{10}(\mathrm{SD})$ cfu of L. monocytogenes/tissue site } \\
\cline { 2 - 3 } Tissue sample & Neutrophil-depleted mice & Control mice \\
\hline Stomach wall & $5.72(1.42)$ & $<2.36 \dagger$ \\
Peyer's patches & $6.42(0.38)$ & $2.69(0.51)$ \\
Small intestine wall & $5.68(0.58)$ & $<2.53_{+}^{+}$ \\
Small intestine wash 1 & $5.96(0.93)$ & $2.72(0.49)$ \\
Small intestine wash 2 & $3.69(0.70)$ & $\mathrm{ND}$ \\
Caecum wall & $5.66(0.64)$ & $3.82(0.41)$ \\
Caecum wash 1 & $5.32(0.41)$ & $\mathrm{ND}$ \\
Caecum wash 2 & $2.85(0.77)$ & $\mathrm{ND}$ \\
Large intestine wall & $6.61(0.48)$ & $4.06(0.60)$ \\
Large intestine wash 1 & $4.65(0.43)$ & $3.63(0.17)$ \\
Large intestine wash 2 & $\mathrm{ND}$ & $\mathrm{ND}$ \\
Liver & $7.61(0.66)$ & $3.83(0.62)$ \\
Spleen & $6.93(0.67)$ & $4.17(0.38)$ \\
\hline
\end{tabular}

Mice depleted of neutrophils by treatment with MAb RB6-8C5 and control mice were inoculated by mouth with $c .5 \times 10^{9} \mathrm{cfu}$ of $L$. monocytogenes. Infected mice were killed on day 3 for bacteriological examination. Data shown are the means of five mean/group

Wash 1 , first $10 \mathrm{ml}$ of luminal wash; wash 2 , last $10 \mathrm{ml}$ of luminal wash; ND, not determined.

${ }^{*}$ Wall dissected free of PP.

$\uparrow$ Listeriae recovered from this site in one of five mice.

\#acteria recovered from this site in two of five mice. 
associated with the gut wall following exhaustive flushing of the luminal contents.

In a complementary experiment, neutrophil-depleted, L. monocytogenes-infected mice failed to infect similarly depleted cohabiting uninfected mice. Moreover, in this experiment, spleen homogenates from deliberately infected neutropenic mice plated on streptomycin-free medium only gave rise to typical L. monocytogenes colonies, while spleen homogenates from uninfected RB6-8C5-treated mice were sterile (data not shown). Given that some species of the normal gut flora grow well on streptomycin-free trypticase-soy agar, these findings suggest that depleting mice of neutrophils does not allow this microflora to breach the gut wall to establish systemic infection.

\section{Histopathology of listeriosis in the guts of neutropenic and control mice}

The results presented in Tables 1 and 2 clearly show that in immunocompromised mice, large numbers of listeriae become firmly associated with the gut wall such that they cannot be dislodged by exhaustive flushing of the gastrointestinal lumen. Conceivably, these wall-associated bacteria could be firmly attached to the gut epithelium. Alternatively, in immunocompromised mice, listeriae might invade the wall of each gut compartment to establish intramural infection. In an attempt to distinguish between these possibilities, a comprehensive histological survey of the washed gut walls of neutropenic and control mice was undertaken. Tissues from mice killed on day 3 of L. monocytogenes infection were examined. By this time, in the stomachs of neutropenic mice, listeria-like bacilli were found growing intramurally as scattered extracellular clumps (Fig. 2a). Severe necrosis was evident in the vicinity of these sites of infection. Individual infectious foci were extensive, but rare. However, it seems reasonable to assume that the $5-6 \log _{10} \mathrm{cfu}$ of L. monocytogenes that would be expected to be firmly associated with the stomach wall at this stage of infection (Table 2) could represent a few scattered intramural microcolonies of the magnitude depicted in Fig. 2a.

In control mice, by contrast, intramural listeriae were not found in the stomach despite an exhaustive search. Of course, this finding was expected given that in these mice $<100$ listeriae could be cultured from the entire stomach wall by day 3 of infection (Tables 1 and 2). Although listeriae were not found, rare focal accumulations of granulocytes were found in the stomach mucosa in control mice (Fig. 2b), and it is presumed that these micro-abscesses developed in response to invading listeriae.

In the small intestine, terminal ileal PP and the gut wall immediately proximal to them were examined for evidence of intramural infection. In neutrophil-depleted mice, intracellular and extracellular listeria-like bacilli were found within lymphoid follicles (Fig. 3a). Lymphocytes were conspicuously depleted in the vicinity of these sites of infection. Furthermore, in the PP of neutropenic mice, some listeriae were associated with dendritic-like cells characterised by their prominent processes and densely staining cytoplasm and nucleoplasm. L. monocytogenes was also found intramurally in the ileal wall at sites remote from these lymphoid nodules (Fig. 3b).

A comprehensive examination of the small intestinal wall of control infected mice revealed the infrequent presence of small focal accumulations of neutrophils in the PP at sites corresponding to sites of conspicuous infection in neutropenic mice (Fig. 4). Bacteria were rarely found in these micro-abscesses.

Fig. 2. Foci of L. monocytogenes infection in the stomach mucosa. a, stomach of a neutropenic mouse. Boxed area in main plate demarcates an extensive focus of intramural infection and associated tissue necrosis in the absence of cellular inflammation. Magnification of main plate, $\times 150$; insets, $\times 1100$. b, focal accumulation of granulocytes in the stomach mucosa of a $L$. monocytogenes-infected control mouse. Magnification of main plate, $\times 150 ;$ inset, $\times 900$. Plastic sections stained with MacNeal's tetrachrome stain.

Fig. 3. Foci of L. monocytogenes infection in the small intestine in neutrophil-depleted mice. a, terminal ileal PP showing lymphocyte depopulation at a site of follicular infection. Intracellular and extracellular bacteria are present at these infectious foci which are devoid of neutrophils. Some bacteria are associated with dendritic cells (inset 1), and others with large rounded mononuclear cells (inset 2). Magnification of main plate, $\times 150$; insets $\times 1400$. b, infectious focus in the gut wall at a site distant from PP. Intracellular and extracellular bacteria are obvious at high magnification (inset). Magnification of main plate, $\times 150$; inset, $\times 1400$. Plastic sections stained with MacNeal's tetrachrome.

Fig. 4. Infectious foci in the PP of control L. monocytogenes infected mice. In control mice infectious foci are indicated by small focal accumulations of neutrophils in the PP. a, Subepithelial micro-abscess. Normal flora bacteria anchored to enterocytes protrude into the lumen. Magnification of main plate, $\times 150$; inset, $\times 1500$. b. Intrafollicular micro-abscess containing listeria-like bacteria (arrows). Magnification, $\times 1500$. Plastic sections stained with MacNeal's tetrachrome.

Fig. 5. Infectious foci in the large intestine. a, In neutropenic mice extensive foci of L. monocytogenes infection were present in lymphoid nodules. Lymphocytes were severely depleted in the vicinity of these infectious foci in which intracellular and extracellular bacilli were found. Magnification of main plate, $\times 150$; inset, $\times 1500$. b, Small neutrophilic micro-abscess in a lymphoid nodule from the bowel of a control infected mouse; arrow depicts a pair of bacilli. Magnification of main plate, $\times 150$; inset, $\times 1500$. Plastic sections stained with Macneal's tetrachrome. 

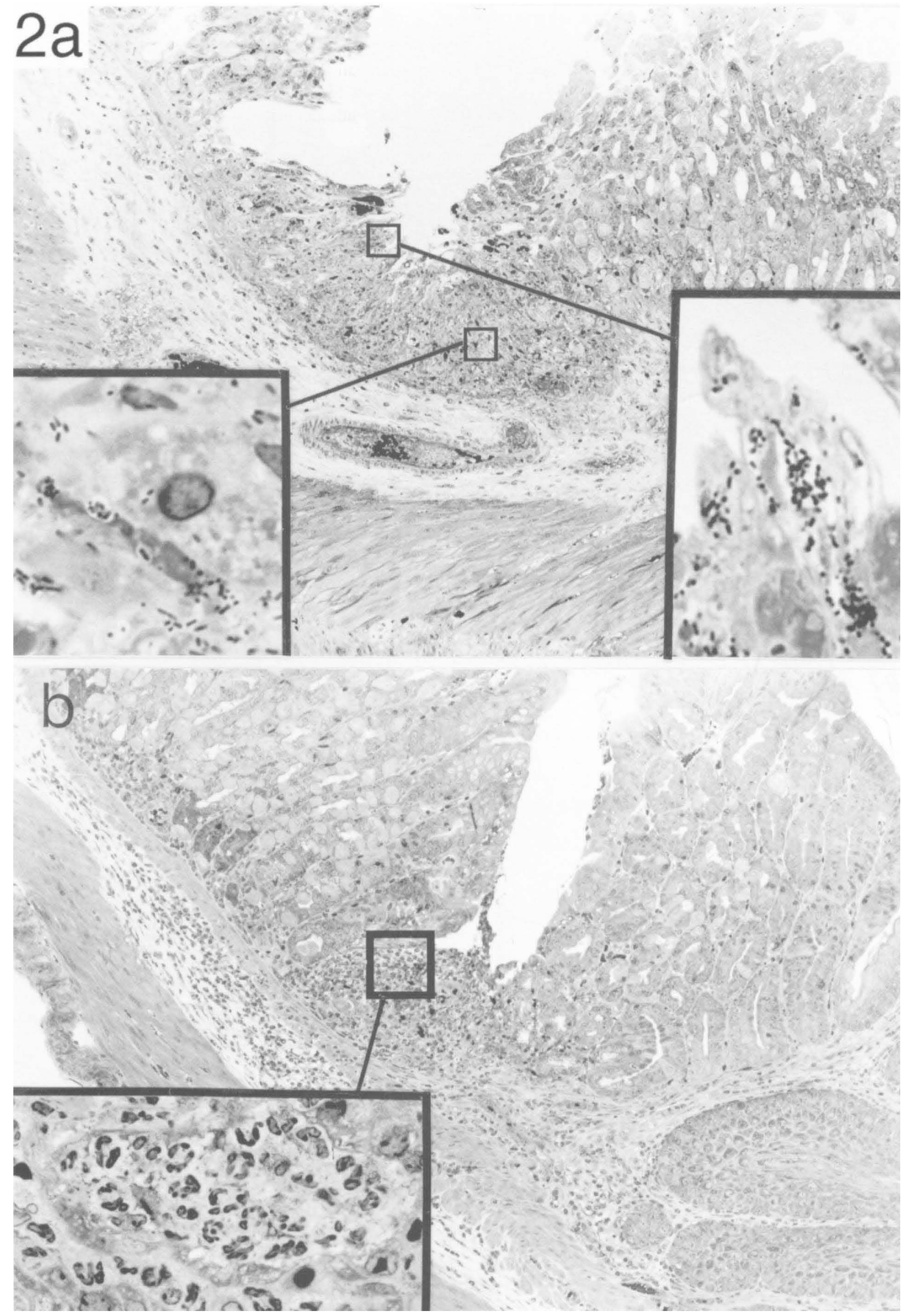
$3 a$
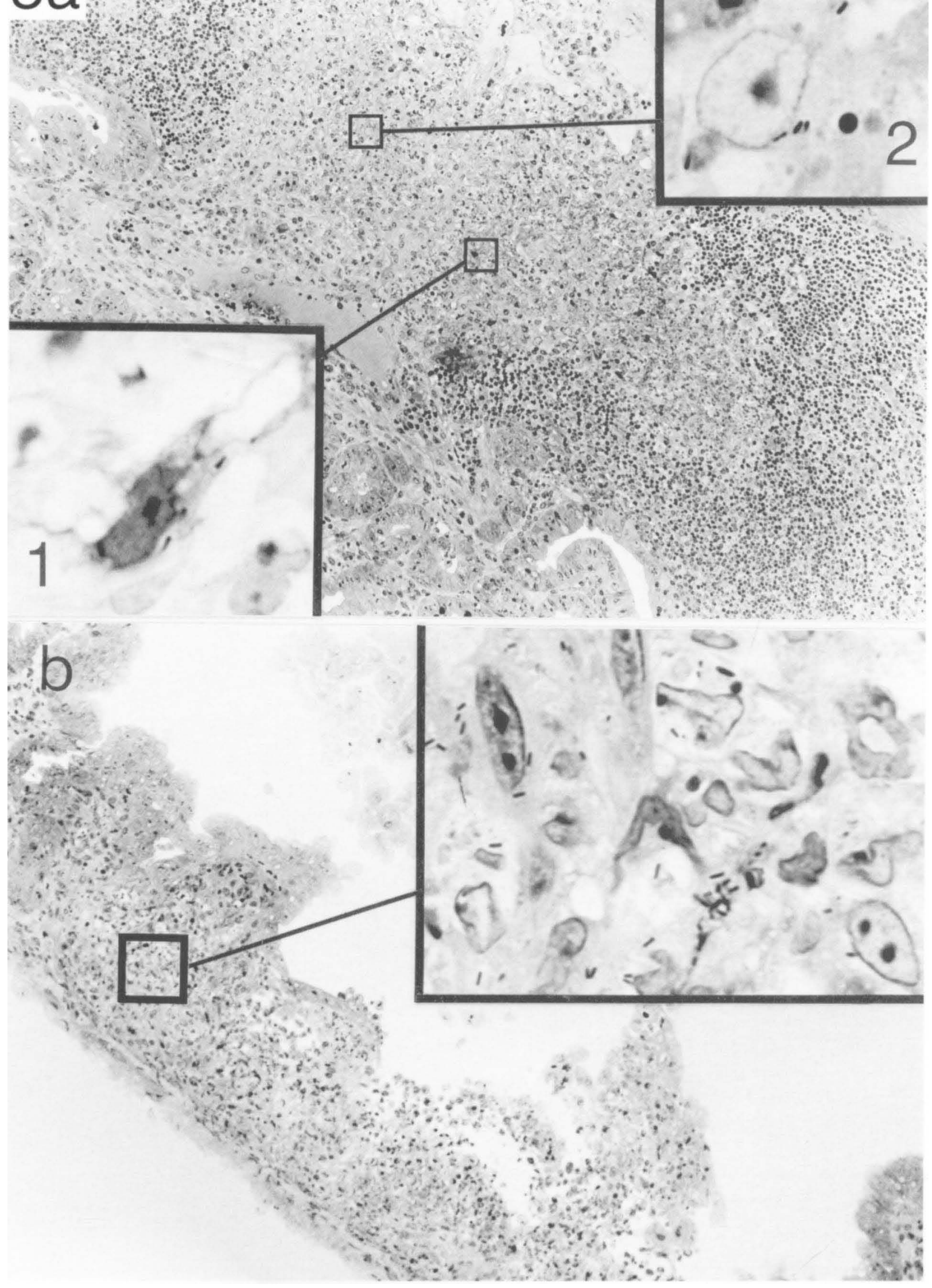


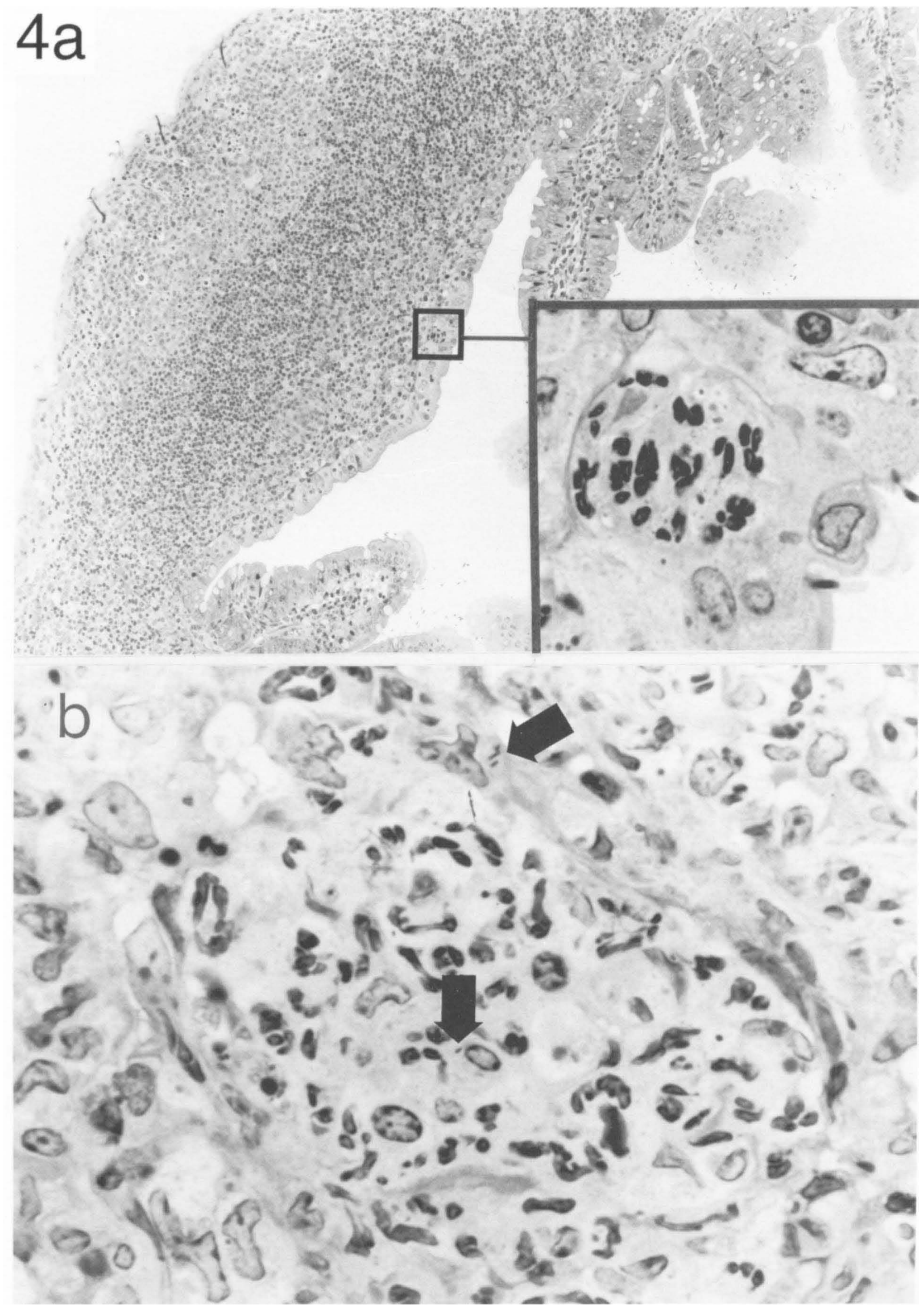



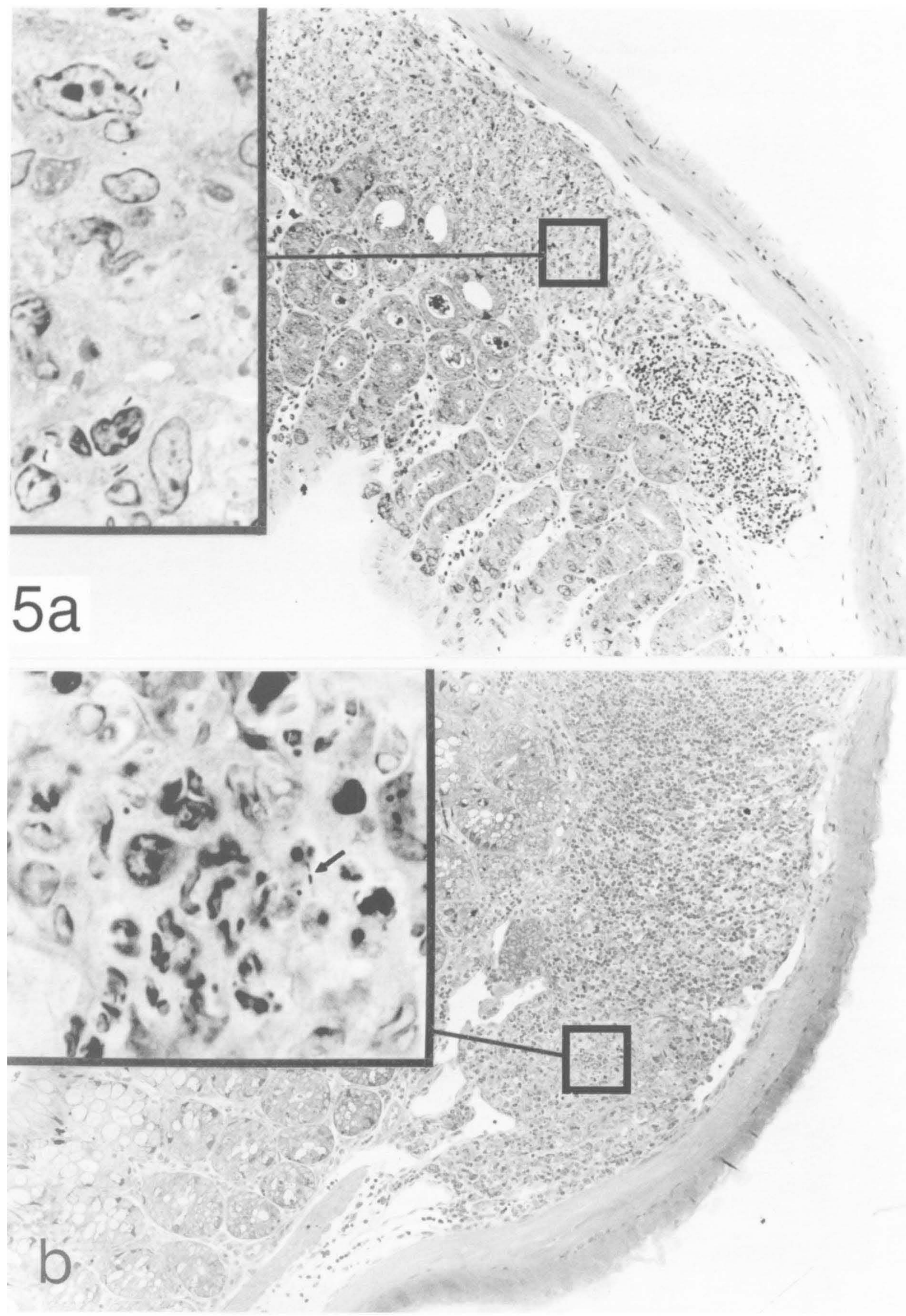
Again, this result was expected given the paucity of viable listeriae that could be cultured from either PP or gut wall in infected immunocompetent mice (Tables 1 and 2). Finally, extensive infectious foci containing scattered intracellular and extracellular listeriae were also found in lymphoid nodules in the large intestines of neutropenic, but not control infected mice (Fig. 5a). In control mice, as in ileal PP, small granulocytic micro-abscesses containing small numbers of bacteria were evident in bowel lymphoid tissue (Fig. 5b).

Thus, at all gut sites examined, the failure of neutrophils to accumulate at foci of intramural $L$. monocytogenes infection allowed the organism to multiply apparently unchecked. In contrast, the focusing of granulocytes at the same sites in control mice correlated with severely restricted bacterial growth.

\section{Discussion}

The results of the present study show that neutrophils and TNF $\alpha$ are essential for early host defence against gastrointestinal as well as systemic stages of orally initiated listeriosis. In the absence of neutrophils or $\mathrm{TNF} \alpha$, far more listeriae were recovered from all gastrointestinal compartments by day 3 of, orally initiated infection than from the same sites in control mice. This implies that L. monocytogenes multiplied essentially unrestrictedly in the GI tracts of mice depleted of neutrophils or deprived of TNF $\alpha$. In immunocompromised mice, in addition to uncontrolled proliferation of initially invading listeriae, redissemination of bacteria from heavily infected livers and spleens back into the gut lumen might also serve to perpetuate enteric infection, as reportedly happens in murine typhoid [26]. Histological examination revealed that many of the listeriae that remained associated with the gut wall of neutropenic mice, and presumably of mice deprived of $\mathrm{TNF} \alpha$, after rigorous washing of the gastrointestinal lumen, were growing intramurally. These organisms probably represent the progeny of the luminal bacteria that invade the gut wall, but which are normally rapidly inactivated by neutrophil- and TNF $\alpha$-dependent defences. In keeping with this interpretation, focal accumulations of neutrophils were found in the gut wall in control mice at sites of $L$. monocytogenes infection, and bacterial proliferation was severely restricted therein. The failure to find many bacteria at these sites in control mice is not surprising, given the demonstrated paucity of viable organisms associated with the gut walls of these mice generally. Moreover, this finding is in keeping with those of others [27] who failed to find intramural L. monocytogenes by immunocytochemistry in the guts of immunocompetent mice infected perorally with this pathogen.

The finding that $L$. monocytogenes invades and proliferates in the stomach wall of neutropenic mice was unexpected, as L. monocytogenes has not otherwise been shown to invade this site. However, heavy colonisation of the gastric lumen by $L$. monocytogenes reportedly [28] occurs in germ-free mice inoculated per os with this organism. Together, these results suggest that, in mice at least, gastric acidity does not rapidly kill all ingested listeriae. According to studies by others [3], with a different strain of L. monocytogenes and a different mouse strain to those used here, listeriae appear preferentially to invade the wall of the small intestine in the vicinity of PP. Other enteroinvasive bacteria, have been shown [5] preferentially to invade epithelial $M$ cells that specifically occupy the epithelium overlying PP. This mode of entry has not yet been formally demonstrated for $L$. monocytogenes, but the present study confirms that PP are selectively vulnerable to colonisation by $L$. monocytogenes. In the PP of neutropenic mice, lymphocyte depopulation occurred in the immediate vicinity of infectious foci. A similar phenomenon occurs in the spleens of neutropenic mice in response to listeria infection in this organ [29]. Moreover, at foci of infection in the PP of neutropenic mice, some L. monocytogenes organisms were intracellularly associated with dendritic-like cells. Cells with similar morphology and staining characteristics were shown recently [29] to be involved in the histopathogenesis of listeriosis in the spleen. In the spleen, these dendritic phagocytes ingest blood-borne listeria in the marginal zone, then transport them into the white pulp of this organ, thereby establishing foci of infection in this splenic compartment. Perhaps these dendritic phagocytes perform a similar role in the PP. In addition to PP, the results of the present study showed that L. monocytogenes can proliferate intramurally elsewhere in the small intestine of immunocompromised hosts. Furthermore, the current study showed that, in immunocompromised hosts, L. monocytogenes can invade and grow in the lymphoid tissue of the large intestine. However, it failed to determine whether lymphoid epithelium is the sole portal of entry for enteroinvasive listeria into the large intestinal wall. Given that others have shown [6] that $L$. monocytogenes can invade the small intestinal wall via unspecialised enterocytes, and that enterocytes line most of the intestinal tract, it is possible that this organism invades the bowel wall via ordinary enterocytes as well as via $\mathrm{M}$ cells. The enhanced susceptibility of the gut walls of immunocompromised mice to colonisation by $L$. monocytogenes demonstrated here might have important clinical implications, given that it is immunosuppressed patients who are most susceptible to this pathogen [1].

In immunocompetent mice, neutrophils and $\mathrm{TNF} \alpha$ act to restrict severely the early proliferation of $L$. monocytogenes. The precise early antimicrobial functions of neutrophils and TNF $\alpha$ at foci of $L$. monocytogenes infection in the gut wall are not known. However, based on their known capabilities, 
neutrophils might directly ingest and kill invading bacteria that might otherwise grow as extracellular microcolonies [25]. Neutrophils might also act to destroy infected epithelial cells during enteroinvasion [6], and to destroy cells of the gastrointestinal submucosa and lamina propria that are parasitised later. Destruction of infected parenchymal cells serves to deprive facultative intracellular bacteria of an otherwise permissive environment in which to multiply concealed from host defences. TNF $\alpha$, given its cytotoxic properties, might also participate in the destruction of infected host cells. Moreover, neutrophils might be a major source of this cytokine [30] at sites of enteroinvasion. Finally, it has been suggested $[17,18]$ that neutrophils and TNF $\alpha$ contribute to the severe enteropathology sometimes associated with enteritis induced by enteroinvasive bacteria. Although the results of the present study do not refute this possibility, they imply nevertheless that in the case of listeriosis, the beneficial antimicrobial functions of neutrophils and TNF $\alpha$ at infectious foci in the gut wall outweigh any detrimental effects to the host resulting from collateral tissue damage.

I thank Louise Hartson for her expert technical assistance and diligence, Lynn Ryan for photography, and Drs Pam Dunn and R. North for their helpful advice and discussion. This study was funded by a grant (IHP-42) from the Trudeau Institute.

\section{References}

1. Farber JM, Peterkin PI. Listeria monocytogenes, a food-borne pathogen. Microbiol Rev 1991; 55: 476-511.

2. Miller JK, Burns J. Histopathology of Listeria monocytogenes after oral feeding to mice. Appl Microbiol 1970; 19: 772-775.

3. MacDonald TT, Carter PB. Cell-mediated immunity to intestinal infection. Infect Immun 1980; 28: 516-523.

4. Okamoto M, Nakane A, Minagawa T. Host resistance to an intragastric infection with Listeria monocytogenes in mice depends on cellular immunity and intestinal bacterial flora. Infect Immun 1994; 62: 3080-3085

5. Neutra MR, Kraehenbuhl J-P. Transepithelial transport and mucosal defence I: the role of M cells. Trends Cell Biol 1992; 2: $134-138$.

6. Rácz P, Tenner K, Mérö E. Experimental Listeria enteritis. I. An electron microscopic study of the epithelial phase in experimental Listeria infection. Lab Invest 1972; 26: 694-700.

7. Kaufmann SHE. Immunity to intracellular bacteria. Annu Rev Immunol 1993; 11: 129-163.

8. Conlan JW, North RJ. Neutrophil-mediated dissolution of infected host cells as a defense strategy against a facultative intracellular bacterium. $J$ Exp Med 1991; 174: 741-744.

9. Conlan JW, North RJ. Neutrophils are essential for early antiListeria defense in the liver, but not in the spleen or peritoneal cavity, as revealed by a granulocyte-depleting monoclonal antibody. $J$ Exp Med 1994; 179: 259-268.

10. Czuprynski CJ, Brown JF, Maroushek N, Wagner RD, Steinberg H. Administration of anti-granulocyte mAb RB6$8 \mathrm{C} 5$ impairs the resistance of mice to Listeria monocytogenes infection. J Immunol 1994; 152: 1836-1846.
11. Havell EA. Evidence that tumor necrosis factor has an important role in antibacterial resistance. J Immunol 1989; 143: $2894-2899$.

12. Rogers HW, Unanue ER. Neutrophils are involved in acute, nonspecific resistance to Listeria monocytogenes in mice. Infect Immun 1993; 61: 5090-5096.

13. Rothe J, Lesslauer W, Lötscher $\mathrm{H}$ et al. Mice lacking the tumour necrosis factor receptor 1 are resistant to TNFmediated toxicity but highly susceptible to infection by Listeria monocytogenes. Nature 1993; 364: 798-802.

14. Czuprynski CJ, Brown JF. Effects of purified anti-Lyt-2 mAb treatment on murine listeriosis: comparative roles of Lyt-2 and $\mathrm{L}_{3} 4^{+}$cells in resistance to primary and secondary infection, delayed-type hypersensitivity and adoptive transfer of resistance. Immunology 1990; 71: 107-112.

15. Dunn PL, North RJ. Resolution of primary murine listeriosis and acquired resistance to lethal secondary infection can be mediated predominantly by Thy $-1^{+} \mathrm{CD} 4^{-} \mathrm{CD} 8^{-}$cells. $J$ Infect Dis 1991; 164: 869-877.

16. Emmerling $P$, Finger $H$, Hof $H$. Cell-mediated resistance to infection with Listeria monocytogenes in nude mice. Infect Immun 1977; 15: 382-385.

17. Arnold JW, Niesel DW, Annable CR et al. Tumor necrosis factor- $\alpha$ mediates the early pathology in Salmonella infection of the gastrointestinal tract. Microb Pathog 1993; 14: 217-227.

18. Perdomo OJJ, Cavaillon JM, Huerre M, Ohayon H, Gounon P, Sansonetti PJ. Acute inflammation causes epithelial invasion and mucosal destruction in experimental shigellosis. $J$ Exp Med 1994; 180: 1307-1319.

19. Conlan JW, North RJ. Roles of Listeria monocytogenes virulence factors in survival: virulence factors distinct from listeriolysin are needed for the organism to survive an early neutrophil-mediated host defense mechanism. Infect Immun 1992; 60: $951-957$.

20. Tepper RI, Coffman RL, Leder P. An eosinophil-dependent mechanism for the antitumor effect of interleukin-4. Science 1992; 257: 548-551

21. Johnson LL, VanderVegt FP, Havell EA. Gamma interferondependent temporary resistance to acute Toxoplasma gondii infection independent of CD4+ or CD8+ lymphocytes. Infect Immun 1993; 61: 5174-5180.

22. Dean CJ, Styles JM, Gyure L et al. The production of hybridomas from the gut associated lymphoid tissue of tumour bearing rats. I. Mesenteric nodes as a source of IgG-producing cells. Clin Exp Immunol 1984; 57: 358--364.

23. Nakane A, Minagawa $T$, Kato K. Endogenous tumor necrosis factor (cachectin) is essential to host resistance against Listeria monocytogenes infection. Infect Immun 1988; 56: 2563-2569.

24. Garside P, Bunce C, Tomlinson RC, Nichols BL, Mowat AM. Analysis of enteropathy induced by tumour necrosis factor $\alpha$. Cvtokine 1993; 5: 24-30.

25. Conlan JW, North RJ. Early pathogenesis of infection in the liver with the facultative intracellular bacteria Listeria monocytogenes, Francisella tularensis, and Salmonella typhimurium involves lysis of infected hepatocytes by leukocytes. Infect Immun 1992; 60: 5164-5171.

26. Collins FM. Immunity to enteric infection in mice. Infect Immun 1970; 1: 243-250.

27. Marco AJ, Prats N, Ramos JA et al. A microbiological. histological and immunohistological study of the intragastric inoculation of Listeria monocytogenes in mice. J Comp Pathol $1992 ; 107 ; 1-9$

28. Zachar Z, Savage DC. Microbial interference and colonization of the murine gastrointestinal tract by Listeria monocytogenes. Infect Immun 1979; 23: 168-174.

29. Conlan JW. Early pathogenesis of Listeria monocytogenes infection in the rmouse spleen. $J$ Med Microbiol 1996; 44: 295-302.

30. Cassatella MA. The production of cytokines by polymorphonuclear neutrophils. Immunol Today 1995; 16: 21-26. 